\title{
METABOLISMO DE NITROGÊNIO E PERDAS ENDÓGENAS EM CAPRINOS CRIADOS A PASTO EM REGIÃO DE CAATINGA
}

\author{
Kedes Paulo Pereira ${ }^{1 *}$,Jucelane Salvino de Lima², Dulciene Karla de Andrade silva ${ }^{3}$, Gladston Rafael de Arruda \\ Santos ${ }^{4}$, Fábio Luz Fregadolli ${ }^{1}$, Antonia Sherlânea Chaves Véras ${ }^{5}$ \\ ${ }^{1 *}$ Professor Dr. Centro de Ciências Agrárias, Universidade Federal de Alagoas, BR 104 Norte, Km 85, Rio Largo, AL. CEP 57.000-100. \\ 2 Professora Dra. UNEAL. BR 316, km 87,5 - Bebedouro, CEP 57.500-000 - Santana do Ipanema - Alagoas. \\ ${ }^{3}$ Professora Dra. Universidade Federal rural de Pernambuco / Unidade Acadêmica de Garanhuns. Avenida Bom Pastor, s/n. ${ }^{\circ}$, Bairro Boa \\ Vista - CEP: 55292-270 - Garanhuns - PE. \\ ${ }^{4}$ Professor Dr. Universidade Federal de Sergipe - UFS Cidade Universitária "Prof. José Aloísio de Campos" AV. Marechal Rondon, s/n. \\ ${ }^{5}$ Professora Dra. Universidade Federal Rural de Pernambuco - UFRPE. Rua Dom Manoel de Medeiros, s/n, Dois Irmãos. Recife/PE.
}

*Autor para correspondência: Kedes Paulo Pereira, kedesp@hotmail.com

RESUMO: O trabalho teve como objetivo estimar o balanço de nitrogênio e as perdas endógenas em caprinos criados a pasto na caatinga, sendo realizados dois experimentos: primeiro experimento - época de transição chuva-seca, no período de junho a setembro; e segundo experimento - época de transição seca-chuva de setembro a dezembro. No primeiro experimento foram utilizados 16 caprinos sem padrão de raça definida, castrados, com peso corporal médio inicial de $16 \mathrm{~kg}$, alocados em dois tratamentos: pastejo à vontade e pastejo restrito. No segundo experimento foram utilizados 18 caprinos sem padrão de raça definida, castrados, com peso vivo médio inicial de $15,5 \mathrm{~kg}$, distribuídos em três tratamentos: pastejo à vontade sem suplementação; pastejo à vontade mais suplementação e pastejo restrito. Foi realizada análise de variância e comparação das médias utilizando o teste $F$ no primeiro experimento e Tukey para o segundo experimento a 5\% de probabilidade utilizando-se o Sistema de Análises Estatísticas e Genéticas SAEG 9,0. Não diferiu a proteína bruta e nitrogênio consumido no primeiro experimento, diferindo no segundo experimento. Foi detectada diferença entre tratamentos para proteína bruta fecal e nitrogênio fecal no primeiro experimento e não no segundo experimento. $O$ volume urinário variou nos dois experimentos. $O$ nitrogênio urinário também variou nos dois experimentos. Diferiram o nitrogênio absorvido e balanço de nitrogênio nos dois experimentos. Não foi constatada diferença para ureia plasmática e urinária no primeiro experimento diferindo para o segundo. As perdas endógenas estimadas não diferiram no primeiro experimento, diferindo no segundo. $O$ balanço nitrogenado de caprinos em condições de pastejo na caatinga, independente de estarem ou não, com restrição alimentar para manutenção do peso vivo e com dieta suplementar, é positivo. Dependendo do sistema de predição utilizado para estimar as perdas endógenas, os resultados diferem substancialmente.

PALAVRAS-CHAVE: caatinga, proteína, ruminantes, suplementação

\section{NITROGEN METABOLISM AND ENDOGENOUS LOSSES IN GOAT BREEDING AND PASTURE IN THE CAATINGA REGION}

ABSTRACT: The objective of this work was to estimate the nitrogen balance and as endogenous losses in goats raised in the pasture in the caatinga. Two experiments were carried out: first experiment - rain-dry transition period, no period from June to September; and second experiment - dry-rain transition season of September and December. In the first experiment, 16 goats with no defined breed pattern were used, castrated, with initial mean body weight of $16 \mathrm{~kg}$, allocated to two treatments: grazing at will and restricted grazing. In the second experiment, 18 goats without castration pattern were used, castrated, with initial mean live weight of $15.5 \mathrm{~kg}$, distributed in three treatments: grazing at will without supplementation; paste in more branches and paste restricted. The analysis of variance and comparisons of means were performed using the $\mathrm{F}$ test in the first experiment and Tukey for the second experiment at $5 \%$ probability of use. System of Statistical and Genetic Analysis SAEG 9,0. It did not differ the crude protein and nitrogen consumed in the first experiment, differing in the second experiment. Differences were detected between treatments for crude fecal protein and fecal nitrogen in the first experiment and not in the second experiment. Urinary volume varied in both experiments. Urinary nitrogen also varied in both experiments. They differed nitrogen absorbed and nitrogen balance in the two experiments. No difference was found for plasma urea and urine first experiment differing for the second. Estimated endogenous sprays did not differ in the first experiment, differing in the second. The nitrogen balance of goats under 
paste conditions in the caatinga, regardless of whether or not they are, with food restriction for maintenance of live weight and supplementary diet, is positive. Depending on the prediction system used to estimate as endogenous losses, the results differ substantially.

KEYWORDS: caatinga, protein, ruminant, supplementation

\section{INTRODUÇÃO}

A caprinocultura vem apresentando uma expansão considerável, principalmente nas regiões semiáridas, apresentando, cada vez mais, uma atividade econômica e rentável pela inserção de novas tecnologias derivadas do conhecimento científico, que tem buscado a transferência de tecnologia de baixo custo.

Visando essas melhorias no sistema de produção, é fundamental saber que a grande maioria da criação de caprinos está na região semiárida, em condições de pasto, na região da Caatinga. 0 conhecimento das respostas metabólicas, como a síntese de proteína microbiana, o balanço de nitrogênio e as perdas endógenas são fatores fundamentais para o conhecimento, mas acurado do perfil metabólico desses animais criados no NE, inclusive possibilitando avaliar as respostas produtivas.

O NRC (2001), o conteúdo de proteína fermentável no ambiente ruminal pode ser derivado da proteína dietética mais a proteína endógena, que é proveniente da reciclagem da ureia, da descamação de células epiteliais e do processo de lise das células microbianas, sendo alguns aminoácidos que escapam da fermentação mais uma fonte de aminoácidos que podem ser absorvidos no intestino.

Há um entendimento de que existe uma relação positiva entre a degradabilidade da proteína da dieta, a produção de amônia, as concentrações sanguíneas e as perdas urinárias de compostos nitrogenados na forma de ureia. A concentração de ureia encontrada na urina está correlacionada positivamente com as concentrações de nitrogênio no plasma e com a ingestão de nitrogênio. Isso se torna importante uma vez que, a concentração da ureia urinária, pode ser um parâmetro sobre 0 comportamento do balanço de nitrogênio nos animais.

A amônia excedente no ambiente ruminal é absorvida pela parede do rúmen, passando para a corrente sanguínea, sendo assim, imediatamente transportada pela veia porta para o fígado, onde é intensamente metabolizada e convertida em ureia, sendo posteriormente excretada na urina ou reciclada através da saliva ou por difusão através da parede do trato digestório (Van Soest, 1994).

Em consequência, para formação da ureia há um aumento nos custos energéticos, resultando em maior gasto de energia para que haja a eliminação da ureia. 0 que se procura então é uma forma de utilização dos alimentos que propiciem uma condição de estabilidade da concentração da amônia ruminal com a maximização da síntese proteica microbiana. Fator importante também é o conhecimento do balanço dos compostos nitrogenados a fim de avaliar o estado nutricional dos caprinos principalmente em condições de pastejo na caatinga com ou sem suplementação a qual reflete diretamente nas respostas produtivas.

O presente trabalho teve como objetivo, avaliar o balanço dos compostos nitrogenados e estimar as perdas endógenas de proteína em caprinos criados a pasto em regime de pastejo à vontade ou restrito com e sem suplementação na Caatinga Pernambucana.

\section{MATERIAL E MÉTODOS}

Foram realizados dois experimentos de acordo com a época do ano: primeiro experimento, época de transição chuva-seca, no período de junho a setembro; e segundo experimento, época de transição seca-chuva, de setembro a dezembro, conduzidos no Centro de Treinamento em Caprino-Ovinocultura pertencente ao Instituto Agronômico de Pernambuco (IPA), na cidade de Sertânia-PE, localizado à latitude $08^{\circ} 03^{\prime} 38^{\prime \prime}$ sul e longitude $37^{0} 13^{\prime} 32$ "oeste. As precipitações pluviométricas no período experimental foram de 17,4 e $0,9 \mathrm{~mm}$ para 0 primeiro e o segundo experimento, respectivamente.

No primeiro experimento foram utilizados 16 caprinos sem padrão de raça definida (SPRD), castrados, com peso corporal (PC) médio inicial de $16 \mathrm{~kg} \pm 0,23 \mathrm{~kg}$ e aproximadamente 90 dias de idade, primeiramente tratados contra endo e ectoparasita, submetidos a período de adaptação ao ambiente e ao manejo durante 15 dias. 0 período experimental teve duração de 105 dias. Os animais foram mantidos em sistema de pastejo em área correspondente a 37 ha de Caatinga, sob lotação contínua.

Os animais foram alocados em dois tratamentos: pastejo à vontade (PA), com acesso irrestrito ao pasto, com bebedouros coletivos; e pastejo restrito (PR), com 
acesso ao pasto durante aproximadamente quatro horas/ dia, ou de acordo com as pesagens intermediárias, com vistas à manutenção do $\mathrm{PC}$, permanecendo o restante do dia contido em baias coletivas com piso de terra batido, providas de bebedouro, sendo suplementados com sal mineral à vontade. Todos os animais foram pesados a cada oito dias para registro da variação de peso durante o experimento.

No segundo experimento foram utilizados 18 caprinos sem padrão de raça definida (SPRD), castrados, com PC médio inicial de 15,5 kg $\pm 0,22 \mathrm{~kg} \mathrm{e}$ aproximadamente 90 dias de idade, também tratados contra endo e ectoparasita e submetidos a um período de adaptação ao ambiente e ao manejo durante 15 dias. 0 período experimental também teve duração de 105 dias divididos em cinco subperíodos de 21 dias. Aárea experimental foi a mesma do primeiro experimento.

Os animais foram alocados em três tratamentos: pastejo à vontade sem suplementação (PA); pastejo à vontade mais suplementação (PAS) com palma forrageira (Opuntia ficus-indica Mill.) variedade gigante + farelo de soja, onde os dois grupos tiveram acesso irrestrito ao pasto, com bebedouro; e pastejo restrito (PR), com acesso ao pasto durante aproximadamente quatro horas/dia, ou de acordo com as pesagens intermediárias com vistas à manutenção do $\mathrm{PC}$, permanecendo o restante do dia, contidos em baias coletivas com piso de terra batido. Para os animais PA também permaneciam em baias coletivas durante a noite e as baias para os que precisavam de suplemento tiveram a mesma dimensão: $1 \mathrm{~m}$ de largura e $2 \mathrm{~m}$ de comprimento, providos de bebedouro e saleiro. Todos os animais foram suplementados com sal mineral à vontade.

Após o período de pastejo, os animais do tratamento PAS eram alocados em um galpão medindo 18,0 m de comprimento e 6,0 m de largura, constituído de vinte e quatro baias individuais com 2,10 m de comprimento, 1,5 m de largura e 1,3 m de altura, confeccionado de madeira e chão batido, equipadas com comedouros onde era fornecida a suplementação. A suplementação fornecida foi na base de $1 \%$ do peso vivo, sendo $50 \%$ de palma forrageira ( 0 . fícus-indica) variedade gigante, cortada manualmente e $50 \%$ de farelo de soja com base na matéria seca, sendo semanalmente ajustadas mediante as pesagens dos animais após jejum médio de 16 horas.

As determinações de matéria seca (MS), proteína bruta $(\mathrm{PB})$, extrato etéreo $(\mathrm{EE})$, matéria mineral $(\mathrm{MM}) \mathrm{e}$ matéria orgânica (MO) foram realizadas de acordo com Silva e Queiroz (2002). Os carboidratos totais (CHT) foram estimados pelas equações descritas por Sniffen et al (1992): $\mathrm{CHT}=100-(\% \mathrm{~PB}+\% \mathrm{EE}+\% \mathrm{MM})$.

Para obtenção dos carboidratos-não-fibrosos (CNF) foi utilizada a equação descrita por Hall (2001), em que CNF = $100-(\% \mathrm{~PB}+\% \mathrm{FDNp}+\% \mathrm{EE}+\% \mathrm{MM})$. As fibras em detergente neutro (FDN) e detergente ácido (FDA), foram determinadas segundo metodologia descrita por Van Soest et al (1991).

$\mathrm{Na}$ Tabela 1, estão apresentadas as composições bromatológica dos ingredientes, do suplemento e da extrusa representando o pasto.

Tabela 1. Composição química dos ingredientes, do suplemento e da extrusa de caprinos mantidos a pasto em caatinga

\begin{tabular}{lccccc}
\hline \multirow{2}{*}{ Item } & & & & \multicolumn{3}{c}{ Extrusa $^{n}$} \\
\cline { 5 - 6 } & Palma & Soja & Suplemento & 1 Exp. & 2 Exp. \\
\hline Matéria seca $^{1}$ & 114 & 890 & 500 & 226 & 231 \\
Proteína Bruta $^{2}$ & 38 & 518 & 277 & 143 & 126 \\
Extrato Etéreo $^{2}$ & 27 & 22 & 20 & 45 & 33 \\
Matéria mineral $^{2}$ & 138 & 69,0 & 104 & 139 & 109 \\
Matéria orgânica $^{2}$ & 862 & 931 & 897 & 859 & 891 \\
Fibra em detergente neutro $^{2}$ & 291 & 192 & 241 & 577 & 601 \\
Fibra em detergente ácido $^{2}$ & 196 & 970 & 147 & 348 & 362 \\
Carboidratos totais $^{2}$ & 797 & 391 & 599 & 673 & 732 \\
Carboidratos não- fibrosos $^{2}$ & 506 & 199 & 358 & 96 & 131 \\
\hline
\end{tabular}

${ }^{1} \mathrm{~g} / \mathrm{Kg}$ na MN $;{ }^{2} \mathrm{~g} / \mathrm{Kg}$ na MS. 
A amostra do pasto foi obtida pela coleta de extrusa (CE) utilizando-se cinco caprinos SPRD, adultos, fistulados no rúmen, com peso vivo médio de $45 \mathrm{~kg}$.

A coleta foi realizada pela manhã às $7 \mathrm{~h}$, após jejum de sólidos de aproximadamente $12 \mathrm{~h}$, sendo retirado todo conteúdo do rúmen dos animais e depositado em um recipiente individualmente. Posteriormente, os animais foram levados à área de pastagem permanecendo por um período de aproximadamente quarenta minutos.

Após o pastejo as amostras foram recolhidas, pesadas e acondicionadas em sacos plásticos devidamente identificados e congeladas a $-15^{\circ} \mathrm{C}$, sendo posteriormente moídos em moinho tipo Willey, com crivo de $1 \mathrm{~mm}$ para posteriores analises químicas.

As fezes foram coletadas durante os últimos cinco experimentos de cada subperíodo diretamente da ampola retal. Após a coleta, as fezes foram secas em estufa de circulação forçada a $55^{\circ} \mathrm{C}$ por aproximadamente 72 horas na própria estação sendo posteriormente, moídas em moinho tipo Willey, em peneiras com crivos de $1 \mathrm{~mm}$, e então encaminhadas ao Laboratório de Nutrição Animal do Departamento de Zootecnia da UFRPE para posteriores analises do nitrogênio fecal.

As amostras foram moídas em moinho tipo Willey, em peneiras com crivos de $1 \mathrm{~mm}$, feita uma amostra composta por animal e por período, e então encaminhadas ao Laboratório de Nutrição Animal do departamento de Zootecnia da Universidade Federal de Minas Gerais (UFMG) para a obtenção da PMSF. $A$ análise do indicador foi realizada segundo a técnica de espectroscopia infravermelha, utilizando-se um espectrofotômetro de infravermelho segundo descrita por Saliba (2005).

A produção de matéria seca fecal (PMSF) foi estimada utilizando-se diariamente doses únicas em cápsulas de $250 \mathrm{mg}$ do indicador externo LIPE $®$, ministrado a sete animais experimentais no experimento 1 e cinco capsulas no experimento 2 , durante os últimos sete dias de cada subperíodo (a partir do $15^{\circ} \mathrm{dia}$ ), sendo as fezes coletadas durante os últimos cinco dias subsequentes ao fornecimento do indicador, diretamente da ampola retal e com sacos de colostomia, acoplados aos animais.

A estimativa do consumo de matéria seca (CMS) para os animais do experimento 1 foi obtida através da equação: CMS (kg/dia) = [(EF) / $(1-$ DIVMS do pasto)] em que: EF = excreção fecal (kg/dia); DIVMS = digestibilidade "in vitro" da matéria seca do pasto; a EF foi estimada com o uso de lignina isolada purificada e enriquecida de Eucaliptus grandis (LIPE®)

Para a estimativa do consumo de matéria seca (CMS) para os animais do experimento 2 foi usada a seguinte equação: CMS (kg/dia) $=[(E F-E F S) /(1-$ DIVMS do pasto)] + CMSS em que: EF = excreção fecal $(\mathrm{kg} / \mathrm{dia}) ; \mathrm{EFS}=$ contribuição de massa fecal do suplemento (kg/dia); DIVMS = digestibilidade "in vitro" da matéria seca do pasto; CMSS = consumo de matéria seca de suplemento ( $\mathrm{kg} / \mathrm{dia}) ;$ a EF também foi estimada com o uso de lignina isolada purificada e enriquecida de Eucaliptus grandis (LIPE®). A EFS foi obtida por meio da diferença entre a EF e o produto da contribuição percentual de matéria seca do suplemento da palma forrageira e do farelo de soja pelas respectivas digestibilidades "in vitro".

A coleta de urina "spot" foi efetuada no último dia de cada subperíodo de coleta, quatro horas após o início do pastejo, durante micção espontânea. A urina foi acondicionada em recipiente com capacidade de $100 \mathrm{~mL}$. Em seguida, foi coletada uma alíquota de $10 \mathrm{~mL}$ de urina, que foi diluída imediatamente em $40 \mathrm{~mL}$ de $\mathrm{H} 2 \mathrm{SO} 4$ a $(0,036 \mathrm{~N})$ e congelada a $-20^{\circ} \mathrm{C}$ para determinar a concentração de creatinina, estimar o volume urinário e os níveis de ureia na urina e nitrogênio total urinário. Logo após a coleta de urina foram coletados amostras de sangue, sendo posteriormente centrifugadas e coletadas o plasma para posteriores análises.

0 nitrogênio absorvido (NABS), expresso em $\mathrm{g} / \mathrm{dia}$, foi obtido pela diferença entre o $\mathrm{N}$ ingerido e 0 excretado nas fezes; enquanto o balanço de nitrogênio (BN) foi determinado deduzindo-se do $\mathrm{N}$ consumido ( $\mathrm{g} /$ dia), o $\mathrm{N}$ excretado nas fezes e urina, em g/dia.

As perdas endógenas (PE) foram estimadas conforme as equações propostas no NRC (2007) e AFRC (1993).

NRC (2007):

- Nitrogênio urinário endógeno NUE $(\mathrm{g} / \mathrm{d})=$ 1,031g/PV0,75;

- Nitrogênio metabólico fecal NMF $(\mathrm{g} / \mathrm{d})=26,7$ g/kg CMS/dia;

- Perdas por descamação PD $(\mathrm{g} / \mathrm{d})=0,2 \mathrm{~g} /$ PV0,6; 
- Exigências de proteína líquida PLm $(g / d)=$ NUE+NMF+PD;

- Perdas endógenas (PE g/d) $=\mathrm{PLm} /$ eficiência de utilização da proteína, de 0,67 para perdas fecais e urinárias e 0,60 para perdas na pele.

AFRC (1993):

- Nitrogênio endógeno basal NEB $(\mathrm{g} / \mathrm{d})=$ $6,25^{*} 0,35^{*} \mathrm{PV} 0,75 / 1,00$ (g/d);

- Perdas por descamação PD $(\mathrm{g} / \mathrm{d})=$ $6,25^{*} 0,018^{*} \mathrm{PV} 0,75 / 1,00$ (g/d);

- Perdas endógenas $(P E g / d)=N E B+P D$ ou 2,3PV0,75 (g/d).
0 delineamento experimental utilizado para os dois períodos foi o inteiramente casualizado. No primeiro experimento, foram utilizados dois tratamentos com 8 repetições e no segundo, três tratamentos com cinco repetições para o PAe PR e oito repetições para o PAS. Foi realizada análise de variância e comparação das médias utilizando o teste de Tukey para os dois experimentos a $5 \%$ de probabilidade utilizando-se 0 Sistema de Análises Estatísticas e Genéticas SAEG 9,0 (UFV 2007).

\section{RESULTADOS E DISCUSSÃO}

Não foi constatada significância $(P>0,05)$ para proteína bruta consumida $(\mathrm{PBC} \mathrm{Kg} / \mathrm{d})$ e nitrogênio consumido (Nc g/d) entre os tratamentos no primeiro experimento (Tabela 2).

Tabela 2. Balanço de nitrogênio em caprinos sob pastejo com e sem suplementação na região semiárida brasileira

\begin{tabular}{|c|c|c|c|c|c|}
\hline \multirow{2}{*}{ Itens } & \multicolumn{3}{|c|}{ Tratamentos } & \multirow{2}{*}{ CV } & \multirow{2}{*}{$P$} \\
\hline & PA & PAS & PR & & \\
\hline & \multicolumn{3}{|c|}{ Primeiro Experimento } & & \\
\hline $\mathrm{PBc}(\mathrm{kg} / \mathrm{d})$ & 0,08 & - & 0,08 & 4,4 & $\mathrm{~ns}^{*}$ \\
\hline $\mathrm{Nc}(\mathrm{g} / \mathrm{d})$ & 13,39 & - & 13,17 & 4,4 & $\mathrm{~ns}^{*}$ \\
\hline $\mathrm{PBf}(\mathrm{kg})$ & 0,04 & - & 0,04 & 6,9 & 0,00387 \\
\hline $\mathrm{Nf}(\mathrm{g} / \mathrm{d})$ & 7,29 & - & 6,39 & 6,9 & 0,00387 \\
\hline $\mathrm{Vu}(\mathrm{L} / \mathrm{d})$ & 4,89 & - & 3,79 & 37,3 & 0,00323 \\
\hline $\mathrm{Nu}(\mathrm{g} / \mathrm{d})$ & 2,27 & - & 1,28 & 50,9 & 0,04416 \\
\hline $\operatorname{Nabs}(g / d)$ & 6,10 & - & 6,77 & 6,0 & 0,00661 \\
\hline \multirow[t]{2}{*}{$\mathrm{BN}(\mathrm{g} / \mathrm{d})$} & 3,83 & - & 5,49 & 23,3 & 0,01435 \\
\hline & \multicolumn{3}{|c|}{ Segundo Experimento } & & \\
\hline $\mathrm{PBC}(\mathrm{kg} / \mathrm{d})$ & $0,078_{b}$ & $0,711_{a}$ & $0,083_{b}$ & 11,5 & 0,00000 \\
\hline $\mathrm{Nc}(\mathrm{g} / \mathrm{d})$ & $12,49_{b}$ & $113,76_{a}$ & $13,39_{b}$ & 11,5 & 0,00000 \\
\hline $\mathrm{PBf}(\mathrm{kg})$ & $0,026_{a}$ & $0,228_{a}$ & $0,027_{\mathrm{a}}$ & 19,5 & $n s^{*}$ \\
\hline $\mathrm{Nf}(\mathrm{g} / \mathrm{d})$ & $4,20 \mathrm{a}$ & $3,64 a$ & $4,39 a^{a}$ & 19,5 & $\mathrm{~ns}^{*}$ \\
\hline $\mathrm{Vu}(\mathrm{L} / \mathrm{d})$ & $5,40_{a}$ & 5,16 & $3,82_{b}$ & 10,8 & 0,00040 \\
\hline $\mathrm{Nu}(\mathrm{g} / \mathrm{d})$ & $2,23_{b}$ & $3,62_{a}$ & $1,65_{b}$ & 23,6 & 0,00015 \\
\hline $\operatorname{Nabs}(g / d)$ & $8,30_{b}$ & $110,13_{a}$ & $9,00_{b}$ & 13,7 & 0,00000 \\
\hline $\mathrm{BN}(\mathrm{g} / \mathrm{d})$ & $6,07_{b}$ & $106,50_{a}$ & $7,35_{b}$ & 14,4 & 0,00000 \\
\hline
\end{tabular}

Pastejo a vontade (PA); pastejo a vontade mais suplementação (PAS); pastejo restrito (PR); coeficiente de variação (CV); significância (P); proteína bruta consumida (PBC); nitrogênio consumido (Nc); proteína bruta fecal (PBf); nitrogênio fecal (Nf); volume urinário (Vu); nitrogênio absorvido (Nabs); balanço de nitrogênio (BN); " não significativo (NS).

No entanto, avaliando o segundo experimento, foi observada significância $(P<0,05)$ para $\mathrm{PBc}(\mathrm{Kg} / \mathrm{d})$ e Nc $(\mathrm{g} / \mathrm{d})$ com maiores médias para o PAS em relação ao PA e PR, não havendo diferença entre esses últimos. Provavelmente, as maiores médias apresentadas para os animais do PAS foi devido ao fornecimento da suplementação, o que culminou em maior consumo de matéria seca com médias de 629,$7 ; 777,2$ e 607,7 g/dia para PA, PAS e PR, respectivamente. 
Contudo, relacionando esses resultados com a PBc e o Nc nos dois experimentos e, levando-se em consideração os tratamentos PA e PR, observase que não houve uma diferença significativa ( $P$ $>0,05$ ), indicando que este comportamento pode estar relacionado com o comportamento ingestivo e a versatilidade dos caprinos em equilibrar sua dieta, principalmente nos períodos de escassez de forragens, Demonstrando um importante indicativo das características de no comportamento ingestivo desses animais nessas áreas.

Para PBf e Nf, foi verificada significância $(P<0,05)$ entre os tratamentos com maiores médias para o PA em relação ao PR no primeiro experimento, não sendo observada diferença significativa $(P>0,05)$ entre os tratamentos no segundo experimento paras as mesmas variáveis.

Segundo o NRC (2007), o N encontrado nas fezes é derivado das células microbianas formadas no intestino grosso, da excreção enzimática e da fonte de $\mathrm{N}$ do alimento que não foi degradado no trato gastrintestinal. Moreno et al (2010), avaliando o balanço de nitrogênio em cordeiros alimentados com silagem de milho ou cana-de-açúcar em dois níveis de concentrado, também não observaram diferenças do $\mathrm{N}$ fecal.

Foi constada diferença significativa $(P<0,05)$ para o volume urinário (Vu), para ambos experimentos, apresentando maiores médias para PA em relação ao PR no primeiro e, no segundo experimento, maiores médias para o PA e PAS em relação ao $P R$, não havendo diferença entre os dois primeiros.

Como o VU estimado está associado à excreção de creatinina e, essa, por sua vez, diretamente relacionada com o peso vivo, provavelmente o peso influenciou para que houvesse o comportamento apresentado.

O nitrogênio urinário $(\mathrm{Nu})$ excretado pelos animais do primeiro experimento apresentou significância $(P<0,05)$ entre os tratamentos. 0 mesmo comportamento foi observado para o NU para os animais do segundo experimento com maiores médias para o PAS em relação a PA e PR, não diferindo entre os dois últimos.

Chalupa et al. (1970) relataram que maiores excreções nitrogenadas via urina são decorrentes de excesso de $\mathrm{N}$ solúvel na dieta, podendo ser observado nos dois experimento o maior aporte de $\mathrm{N}$ para os animais do PA e PAS para o primeiro e segundo experimento, respectivamente, houve também um aumento dos níveis de $\mathrm{N}$ na urina.

Para o Nabs, foi observada diferença significativa $(P<0,05)$ para os dois experimentos, apresentando maiores médias para o PR em relação ao PA para o experimento 1.

Esse comportamento pode está relacionado com um maior escape de $\mathrm{N}$ no trato gastrintestinal aumentando sua concentração nas fezes, 0 que acarretou em uma menor absorção de $\mathrm{N}$ no tratamento do PA. Quanto ao do experimento 2, foram encontradas maiores médias para o PAS em relação ao PA e PR, não apresentando diferença estatística entre esses dois.

O Nabs é caracterizado pela diferença entre 0 $\mathrm{N}$ que foi consumido mais o $\mathrm{N}$ microbiano encontrado no intestino delgado e o $\mathrm{N}$ encontrado nas fezes que reflete o que não foi absorvido. Isso está relacionado com a digestibilidade das fontes de $\mathrm{N}$ consumido, bem como, com o equilíbrio de $\mathrm{N}$ e energia para os microrganismos ruminais.

Como, provavelmente, os animais do PAS segundo experimento, tiveram maior equilíbrio de $\mathrm{N}$ e energia, pode ter ocorrido maior degradação do alimento, disponibilizando uma maior absorção de $\mathrm{N}$.

O BN também diferiu entre tratamentos $(P<0,05)$ apresentando maiores médias para o $P R$ em relação ao PA nos animais do experimento 1. Possivelmente isso se deveu em virtude da capacidade de reciclagem de $\mathrm{N}$ por esses animais, mesmo não sendo constatadas diferenças quando se observa os resultados da ureia urinária (UU) na Tabela 4, pode ser constatado que todas as médias apresentadas para essa variável sempre se encontra abaixo das médias do PA.

Além disso, observa-se também que ocorreu uma diminuição na concentração de urina com diferença significativa, com menor volume para o $\mathrm{PR}$, evidenciando a capacidade desses animais na diminuição dessas perdas no momento de escassez.

Para os animais do segundo experimento, foi observada diferença $(P<0,05)$ para o PAS em relação aos demais tratamentos, os quais não diferiram entre si. No entanto, BN foi positivo em todos os tratamentos, tanto para os animais do experimento 1 quanto para 
os do experimento 2, indicando que houve retenção de proteína no organismo animal.

Faz-se importante mencionar que a resposta apresentada pelos animais do PAS, está atrelada a suplementação oferecida a qual foi de apenas $1 \%$ do peso vivo, obtendo-se uma superioridade significativa em todas as variáveis analisadas, comprovando a importância da resposta obtida quando há aporte nutricional em épocas de escassez, ou até mesmo nos períodos de provimento de alimentos, como tem sido observado, quando comparados os resultados com os animais do primeiro experimento.

A determinação do balanço de nitrogênio é útil para avaliar se 0 animal se encontra em equilíbrio nitrogenado e se, sob determinadas condições, ocorre ganho ou perda de $\mathrm{N}$ (Kolb, 1984). A condição do balanço positivo de $\mathrm{N}$ nos animais experimentais se torna relevante porque indica que proporcionou retenção de $\mathrm{N}$, principalmente para os animais do PR nas duas épocas do ano.

Não foi observada diferença significativa $(P>0,05)$ para UP e NUP, entre os tratamentos no primeiro experimento (Tabela 3). A não significância provavelmente está relacionada à proteína bruta consumida (PBc), os quais não diferenciaram entre os tratamentos. No entanto, observando-se os resultados dos animais do experimento 2, constatou-se diferença significativa $(P<0,05)$ diferindo entre o PAS em relação ao PA e PR e não diferindo entre esses últimos, com maiores médias para o PAS.

Tabela 3. Metabólitos sanguíneos e urinários em caprinos sob pastejo com e sem suplementação na caatinga

\begin{tabular}{|c|c|c|c|c|c|}
\hline \multirow{2}{*}{ Item } & \multicolumn{3}{|c|}{ Tratamento } & \multirow{2}{*}{ CV } & \multirow{2}{*}{$P$} \\
\hline & PA & $\mathrm{PA}+\mathrm{S}$ & PR & & \\
\hline & \multicolumn{3}{|c|}{ Experimento 1} & & \\
\hline UP (mg/dL) & 18,97 & - & 20,05 & 43,8 & ns \\
\hline UP (mg/PV) & 46,67 & - & 43,78 & 67,6 & ns \\
\hline UP (mg/PV0,75) & 98,54 & - & 89,80 & 67,1 & ns \\
\hline NUP (mg/dL) & 8,84 & - & 9,35 & 43,8 & ns \\
\hline NUP (mg/PV) & 21,75 & - & 20,40 & 67,8 & ns \\
\hline NUP (mg/PV0,75) & 45,92 & - & 41,85 & 67,1 & ns \\
\hline UU (mg/dL) & 463,80 & - & 396,99 & 81,7 & ns \\
\hline UU (mg/PV) & 1141,59 & - & 938,25 & 95,7 & ns \\
\hline UU (mg/PV0,75) & 2387,39 & - & 1915,59 & 94,9 & ns \\
\hline NUU (mg/dL) & 216,13 & - & 185,00 & 81,7 & ns \\
\hline NUU (mg/PV) & 531,98 & - & 437,22 & 95,6 & ns \\
\hline \multirow[t]{2}{*}{ NUU (mg/PV 0,75$)$} & 1112,53 & - & 892,66 & 95,1 & ns \\
\hline & \multicolumn{3}{|c|}{ Experimento 2} & & \\
\hline UP (mg/dL) & $21,35_{b}$ & $38,78_{a}$ & $22,93_{b}$ & 37,3 & 0,00000 \\
\hline UP (mg/PV) & $73,20_{b}$ & 119,62 & $58,07_{b}$ & 58,5 & 0,00002 \\
\hline UP (mg/PV0,75) & $145,33_{b}$ & $243,70_{a}^{a}$ & $113,96_{b}$ & 58,7 & 0,00000 \\
\hline $\operatorname{NUP}(\mathrm{mg} / \mathrm{dL})$ & $9,95_{b}$ & $18,07_{\mathrm{a}}^{a}$ & $10,68_{b}$ & 37,3 & 0,00000 \\
\hline NUP (mg/PV) & $34,11_{b}$ & $55,74_{a}$ & $27,06_{b}$ & 58,5 & 0,00002 \\
\hline $\operatorname{NUP}(\mathrm{mg} / \mathrm{PV} 0,75)$ & $67,72_{b}$ & $113,56_{a}$ & $53,11_{b}$ & 58,7 & 0,00000 \\
\hline $\mathrm{UU}(\mathrm{mg} / \mathrm{dL})$ & $56,38_{b}$ & $147,53_{a}^{a}$ & $74,34_{b}$ & 81,2 & 0,00004 \\
\hline UU (mg/PV) & $184,60_{b}$ & $370,73_{a}$ & $188,60_{b}$ & 94,9 & 0,00428 \\
\hline UU (mg/PV0,75) & $366,44_{b}$ & $749,28{ }_{a}$ & $372,15_{b}$ & 94,3 & 0,00294 \\
\hline $\mathrm{NUU}$ (mg/dL) & $26,27_{b}$ & $69,75_{a}$ & $34,64_{b}$ & 81,2 & 0,00004 \\
\hline NUU (mg/PV) & $86,02_{b}$ & $172,76_{a}$ & $87,88_{b}$ & 94,9 & 0,00428 \\
\hline NUU (mg/PV0,75) & $170,76_{b}$ & 349,17 & $173,42_{b}$ & 94,6 & 0,00294 \\
\hline
\end{tabular}

Pastejo a vontade (PA); pastejo a vontade mais suplementação (PAS); pastejo restrito (PR); coeficiente de variação (CV); significância (P); ureia plasmática (UP); N-úreico plasmático (NUP); ureia urinária (UU); N-úrico urinário (NUU); * não significativo (NS). 
Tabela 4. Perdas endógenas estimadas em caprinos sob pastejo com e sem suplementação na caatinga

\begin{tabular}{|c|c|c|c|c|c|}
\hline Item & PA & PAS & PR & CV & $P^{*}$ \\
\hline \multicolumn{6}{|c|}{ Experimento 1} \\
\hline & \multicolumn{3}{|c|}{ NRC 2007} & & \\
\hline $\operatorname{NUE}(g / d)$ & $6,48_{a}$ & & $5,94_{b}$ & 2,0 & 0,00000 \\
\hline $\operatorname{NMF}(g / d)$ & 19,61 & & 19,19 & 4,4 & ns \\
\hline $\mathrm{PD}(\mathrm{g} / \mathrm{d})$ & $0,051_{\mathrm{a}}$ & & $0,055_{b}$ & 2,1 & 0,00000 \\
\hline PLm & 26,15 & & 25,18 & 3,4 & $n s^{* *}$ \\
\hline \multirow[t]{2}{*}{ PMm } & 39,03 & & 37,59 & 3,4 & ns \\
\hline & \multicolumn{3}{|c|}{ AFRC 1993} & & \\
\hline NEB & $21,46_{a}$ & & $18,76_{b}$ & 3,5 & 0,00000 \\
\hline $\mathrm{PD}$ & $1,10_{a}$ & & $0,96_{b}$ & 3,5 & 0,00000 \\
\hline \multirow[t]{3}{*}{ PMm } & $22,56 a$ & & $19,73_{b}$ & 3,5 & 0,00000 \\
\hline & \multicolumn{3}{|c|}{ Experimento 2} & & \\
\hline & \multicolumn{3}{|c|}{ NRC 2007} & & \\
\hline NUE & $6,04_{b}$ & $6,72_{a}$ & $5,73_{b}$ & 5,2 & 0,00023 \\
\hline NMF & $20,26_{b}$ & $33,97 \mathrm{a}$ & $21,15_{b}$ & 7,9 & 0,00000 \\
\hline$P D$ & $0,055_{a}$ & $0,049_{b}$ & $0,058_{a}$ & 5,2 & 0,00024 \\
\hline PLm & $26,35 \mathrm{~b}$ & $40,74 a$ & $26,94_{b}$ & 6,8 & 0,00000 \\
\hline \multirow[t]{2}{*}{$\mathrm{PMm}$} & $39,33_{b}$ & $60,80_{a}$ & $40,20_{b}$ & 6,8 & 0,00000 \\
\hline & \multicolumn{3}{|c|}{ AFRC 1993} & & \\
\hline NEB & $19,18_{b}$ & $22,77_{\mathrm{a}}$ & $17,48_{b}$ & 8,6 & 0,00023 \\
\hline $\mathrm{PD}$ & $0,99_{b}$ & $1,17_{a}$ & $0,90_{b}$ & 8,6 & 0,00023 \\
\hline PMm & $20,16_{b}$ & $23,93 \mathrm{a}$ & $18,31_{b}$ & 8,6 & 0,00023 \\
\hline
\end{tabular}

Pastejo a vontade (PA); pastejo a vontade mais suplementação (PAS); pastejo restrito (PR); coeficiente de variação (CV); significância (P); nitrogênio urinário endógeno (NUE); nitrogênio metabólico fecal (NMF); perdas por descamação (PD); proteína líquida para mantença (PLm); proteína metabolizável para mantença (PMm); nitrogênio endógeno basal (NEB); " não significativo (NS).

Como o Nc apresentou-se indiferente entre os tratamentos nos animais do primeiro experimento, o que pode ter ocorrido foi uma similar produção de amônia pelos microrganismos, absorvidos pela parede do rumem e consequentemente apresentando concentrações próximas no plasma sanguíneo, o que é considerado como relevante quando se observam os animais do PR, onde, mesmo estando nessas condições, conseguiram manter os níveis de $\mathrm{N}$ plasmático próximos aos animais do $\mathrm{PA}$.

O mesmo comportamento foi constatado nos animais no segundo experimento, entre os tratamentos PA e PR, uma vez que, também, não foi observada significância para PBc e Nc entre esses tratamentos. Contudo, os resultados para o PAS foram superiores aos demais tratamentos. Também corroborando com o relato feito por Van Soest (1994), mostrando a capacidade dos caprinos selecionarem com eficiência, os alimentos consumidos, independentes das condições de manejo imposta pelos tratamentos aos animais experimentais e nas diferentes épocas do ano, principalmente considerando-se animais a pasto.

Possivelmente, a capacidade de reciclagem do $\mathrm{N}$ também pode ser considerada como outro fator que pode ter contribuído para o comportamento apresentado, uma vez que, em condições de estresse alimentar, os caprinos se apropriam de um aumento na capacidade de reciclagem de nutrientes, evitando perdas, com o objetivo de suprir suas necessidades nutricionais.

A concentração de Nc por sua vez pode ter contribuído diretamente na concentração de UP, uma vez que Preston (1965) relata que o consumo de $\mathrm{N}$ influencia contundentemente as concentrações de ureia no plasma sanguíneo. Segundo Visek (1979), Church (1988) e Swenson e Reece (1996), o fígado produz ureia, tanto da amônia absorvida na parede do rúmen, quanto da amônia gerada na deaminação de 
aminoácidos oriundos da absorção pós-ruminal ou do metabolismo sistêmico de proteína, ácidos nucléicos e outros compostos nitrogenados. Posteriormente, segue para a circulação sangüínea e pode ser reciclada pela parede ruminal e pela saliva voltando para o rúmen.

As médias de UP foram inferiores aos encontrados por Alves et al. (2007), que observaram valores de $44,25 \mathrm{mg} / \mathrm{dL}$ em tratamento com $0 \%$ de ureia, avaliado quatro horas após a alimentação em cabras. Não foi observada diferença significativa $(P>0,05)$ para UU e NUU entre os tratamentos para os animais do primeiro experimento. Porém, no segundo experimento, as maiores médias foram obtidas para o tratamento PAS em relação ao PA e $\mathrm{PR}$, não sendo observada significância para esses dois últimos. É importante ressaltar que não houve diferença significativa da UU entre o PA e PR tanto no primeiro quanto no segundo experimento, levando ao entendimento de que se torna importante observar esse comportamento com os caprinos a pasto com e sem restrição alimentar, uma vez que a concentração da UU nos animais do PR é um indicativo da capacidade desses animais em reciclar a ureia, a fim de evitar perdas de ureia pela urina, principalmente nos períodos de escassez de alimentos.

Segundo Harmeyer e Martens (1980), quando há diminuição na concentração de ureia do plasma sanguíneo, há uma diminuição correspondente na quantidade de ureia filtrada no glomérulo, e um aumento da reabsorção tubular de ureia, o que, provavelmente, deve ter ocorrido com os animais do PR nos dois períodos do ano.

Cavalcante(2006) relatou que as concentrações de ureia urinária estão diretamente correlacionadas com a ingestão de N, o que foi observado no presente trabalho para os dois períodos de transição.

Outro fator que deve ser lavado em consideração é que, no segundo experimento, a suplementação a $1 \%$ PV, influenciou beneficamente, aumentando 0 aporte de nutrientes para esses animais os quais apresentaram maiores concentrações de $\mathrm{UU}$, indicando um maior consumo de $\mathrm{N}, 0$ que foi constatado na Tabela 4, atribuídos contundentemente ao suplemento fornecido.

Eriksson e Valtonen (1982), avaliando a concentração de ureia na urina de caprinos alimentados com dietas com alta e baixa concentração de proteína observou uma menor taxa de filtração glomerular da ureia para os animais que consumiram a dieta com baixa concentração de proteína.

Corroborando com o presente experimento, uma vez que, para os animais do primeiro experimento, não foi observada diferença significativa entre os tratamentos, provavelmente, também, como reflexo da não significância para o Nc pelos animais.

Quando se observaram os resultados dos animais no segundo experimento, a de Eriksson e Valtonen (1982), também está de acordo com os resultados do presente trabalho, uma vez que houve uma maior concentração de UU para os animais do PAS, também sendo um provável reflexo do maior consumo de nitrogênio.

Para o NUE foi observada diferença significativa $(P<0,05)$ tanto para os animais do primeiro quanto para os do segundo experimento (Tabela 4), com maior média para o PA em relação ao PR.

No segundo experimento, foi observado maiores médias para o PAS em relação ao PA e PR, os quais não diferiram entre si.

Segundo o CSIRO (1990), o nitrogênio urinário endógeno é a quantidade de nitrogênio excretada na urina, derivada da oxidação dos aminoácidos e das excreções derivadas do processo de reciclagem de nitrogênio, incluindo a ureia, creatinina, bilirrubina, alantoína, ácido úrico, ácido hipúrico e aminoácido três metil-histidina, sendo as perdas de NUE consideradas inferiores às encontradas no nitrogênio metabólico fecal, o que foi constatado no presente experimento para os dois períodos do ano.

Possivelmente, a maior média encontrada pelo PA nos animais do primeiro experimento apresenta-se em concordância com os dados de Nu apresentado na Tabela 2, sendo observado o mesmo comportamento.

Em relação aos resultados obtidos para o PAS nos animais do experimento 2, pode está relacionado com um maior equilíbrio da relação proteína energia no rumem, proporcionados pela suplementação, aumentando as concentrações séricas dos compostos nitrogenados e conseqüentemente a sua excreção na urina, o que também pode ser comprovado quando se observa os resultados de $\mathrm{Nu}$ na Tabela 3, contribuindo para a maior concentração do NUE, já que também é contabilizado.

Para o NMF, não foi observada diferença significativa $(P>0,05)$ entre os tratamentos para os 
animais do primeiro experimento. No entanto, houve diferença significativa $(P<0,05)$ para os animais do segundo experimento, com maiores médias para o PAS em relação ao PA e PR, os quais não diferiram.

O NMF, segundo o NRC (2007), é derivado das células microbianas formadas no intestino grosso, da excreção enzimática, das células do epitélio, bem como da fonte de proteína do alimento que não foi degradado no trato gastrintestinal.

As perdas por descamação são derivadas das células epiteliais do trato gastrintestinal (NRC, 2007). O tempo de restrição para o $\mathrm{PR}$, tanto para os animais do primeiro quanto do segundo experimento, não foi suficiente para afetar essa variável.

No caso dos animais do segundo experimento, a significância pode está relacionada com 0 maior aporte de nutrientes derivada da suplementação dada aos animais do PAS apresentando por sua vez um aumento da $\mathrm{N}$ encontrado nas fezes.

As PD diferiram $(P<0,05)$ entre os tratamentos dos animais do primeiro experimento com maiores médias para o PR em relação ao PA. 0 mesmo comportamento ocorreu com os animais do segundo experimento com maiores médias também para o PA e PR em relação ao PAS, não diferindo para os dois primeiros tratamentos relatados.

As PLm também não diferiram $(P>0,05)$ entre os tratamentos do PAe PR para os animais do primeiro experimento. Para os animais do segundo experimento, foi observada diferença significativa $(P>0,05)$ cujas maiores médias foram obtidas para o PAS em relação ao PA e PR.

Observando os resultados encontrados entre o PA e PR foi encontrado em valores absolutos maiores médias para o PR no segundo experimento, mostrando, de certa forma, a capacidade de adaptabilidade desses animais em maximizar 0 consumo de $\mathrm{N}$ e manter em equilíbrio as excreções dos compostos nitrogenados quando se encontram em condições nutricionais desfavoráveis.

A estimativa da PMm, segundo o AFRC (1993), foi obtida primeiramente calculando-se o $\mathrm{N}$ endógeno basal (NEB), onde foi encontrada significância $(P<0,05)$, com maiores médias para o PA em relação ao PR para os animais do primeiro experimento. Comportamento semelhante foi observado para os animais do segundo experimento; no entanto, com maiores médias para 0
PAS em relação ao PA e PR, não tendo sido detectado diferenças diferenciando entre os dois últimos.

Segundo o AFRC (1993), o NEB consiste na soma do NUE e parte do NMF. Se forem comparados os resultados obtidos pelo NRC (2007), somando os NUE e o NMF, pode-se observar em valores absolutos, as médias de 26,09 e 25,13 para o PA e PR respectivamente, para os animais do primeiro experimento.

No entanto, para os animais do segundo experimento foram obtidas médias de 26,3; 40,69 e 26,88 para o PA, PAS e PR respectivamente. Esses valores apresentam-se superiores as médias do NEB obtidos pelo AFRC (1993). Isso em virtude das metodologias e conceitos serem diferentes para a estimativa do NMF.

Os PD apresentaram superioridade significativa $(\mathrm{P}<0,05)$ para o $\mathrm{PA}$ em relação ao $\mathrm{PR}$ nos animais do primeiro experimento, não sendo observado essa significância para os mesmos tratamentos nos animais do segundo experimento, que apresentou diferença significativa $(P<0,05)$ com maior média para o PAS.

A PMm apresentou diferença significativa $(P<0,05)$ com maiores médias para o $P A$ em relação ao PR para os animais do primeiro experimento. Também foi observada diferença para os animais do segundo experimento, com maiores médias para PAS em relação ao PA e PR, não sendo detectada diferença para esses dois últimos.

Comparando-se as PMm obtidas segundo o NRC (2007), em relação às estimadas pelas equações preconizadas pelo AFRC (1993), pode-se observar uma superioridade dos resultados relativos ao sistema americano de exigências nutricionais, chegando no presente trabalho, a um percentual de diferença para PMm de $57,80 \%$ e $52,49 \%$ para o PA e PR e $51,26 \%$; $39,36 \%$ e $45,55 \%$ para o PA, PAS e PR respectivamente, estimado pelo AFRC (1993) em relação ao NRC (2007). Silva e Nóbrega (2008) observaram médias de 38,7 (g/d) de PMm, apresentando-se menores que os observado no presente trabalho, tanto para os animais do primeiro experimento quanto para os animais do segundo experimento, quando estimados pelo NRC (2007). Possivelmente devido à condição de pastejo dos animais, tendo havido um maior gasto de energia para locomoção e sendo, provavelmente, aumentadas as exigências de mantença. 
0 balanço nitrogenado de caprinos em condições de pastejo na Caatinga, independente de estarem ou não, com restrição alimentar para manutenção do peso vivo e com dieta suplementar, é positivo.

Dependendo do sistema de predição utilizado para estimar as perdas endógenas, os resultados diferem substancialmente.

\section{REFERÊNCIAS BIBLIOGRÁFICAS}

AFRC - Agricultural and Food Research Council. Energy and protein requeriments of ruminants. Wallingford: Common wealth Agricultural Bureaux International, 1993.

Alves, N.G.; Torres, C.A.A.; Rodrigues M T, Cecon $P R$, Santos A D F, Siqueira $L G B$, Bitencourt $L L$ and Moraes E A. Efeito do nível de ureia na dieta sobre o desempenho, a qualidade e o estádio de desenvolvimento embrionário em cabras Alpinas. Arquivo Brasileiro de Medicina Veterinária e Zootecnia, 2007, 59, 4, 996-1005.

Cavalcante, M.A.B.; Pereira, O.G.; Valadares Filho, S.C.; Ribeiro, K.G.; Pacheco, L.B.B.; Araújo, D.; Lemos, V.M.C. Níveis de Proteína Bruta em Dietas para Bovinos de Corte: Parâmetros Ruminais, Balanço de Compostos Nitrogenados e Produção de Proteína Microbiana. Revista Brasileira de Zootecnia, 2006, 35, $1,203-210$

Chalupa, W.; Clark, J.; Opliger, P.; Lavker, R. Detoxication of ammonia in sheep fed soy protein or urea. Journal of Nutrition, Bethesda, 1970, 100, 2, 170-176.

Church, D.C. The animal digestive physiology and nutrition. New Jersey: Prentice Hall, 1988, 386 p.

CSIRO - Common wealth Scientific and Industrial Research Organisation. Standing Committee on Agriculture, Ruminants Subcommittee, Feeding standards for Australian livestock. Ruminants. Ed. CSIRO Publishing, East Melbourne, Australia, 1990.

Eriksson, L.; Valtonen, M. Renal Urea Handling in Goats Fed High and Low Protein Diets. Journal of Dairy Science, 1982, 65, 385-389.
Harmeyer, J.; Martens, H. Aspects of urea metabolism in ruminants with reference to the goat. Journal of Dairy Science, 1980, 63, 10, 1707-1728.

Hall, M.B. Recentes avanços em carboidratos não fibrosos na nutrição de vacas leiteiras. In: Simpósio Internacional de Bovinocultura de Leite: Novos conceitos em nutrição. Lavras. Anais... Lavras: Universidade Federal de Lavras, 2001, 149-159.

Kolb, E. Fisiologia veterinária. Guanabara Koogan, Rio de Janeiro, 1984 612p.

Moreno, G.M.B.; Silva Sobrinho, A.G.; Leão, A.G.; Loureiro, C.M.B.; Henrique Leal Perez, H.L.; Rossi, R.C. Desempenho, digestibilidade e balanço de nitrogênio em cordeiros alimentados com silagem de milho ou cana-de-açúcar e dois níveis de concentrado. Revista Brasileira de Zootecnia, 2010, $39,4,853-860$.

NRC - National Research Council. Nutrient requirements of beef cattle. 7.ed. Washington, D.C.: National Academy. 2001, 242p.

NRC - National Research Council. Nutrient Requirements Of Small Ruminants: Sheep, Goats, Cervids, And New World Camelids. Washington, D.C.: National Academy Press, 2007, 384p.

Preston, R.L.; Schnakenberg, D.D.; Pfander, W.H. Protein utilization in ruminants. I. Blood urea nitrogen as affected by protein intake. Journal of Nutrition, 1965, 86, 281.

Saliba, E.O.S. Mini-curso sobre o uso de indicadores. In: TELECONFERÊNCIA SOBRE INDICADORES EM NUTRIÇÃO ANIMAL, 1., 2005. Belo Horizonte. Anais... Belo Horizonte : Escola de Veterinária/ UFMG, 23-35.

Silva, A.M.A.; Nóbrega, G.N. Exigências Nutricionais de Ruminantes em Pastejo. I SIMPAS - I SIMPÓSIO EM SISTEMAS AGROSILVIPASTORIS NO SEMIÁRIDO PPGZ/CSTR/UFCG, 2008.

Silva, D.J.; Queiroz, A.C. Análise de alimentos: métodos químicos e biológicos. Viçosa, MG:UFV. 2002, 165p. 
Sniffen, C.J.; O'Connor, J.D.; Van Soest, P.J.; Fox, D.G.; Russell, J.B. A net carbohydrate and protein system for evaluating cattle diets: II. Carbohydrate and protein availability. Journal of Animal Science, 1992, 70, 3562-3577.

Swenson, M.J.; Reece, W.O. Dukes Fisiologia dos animais domésticos. Rio de Janeiro: Guanabara Koogan, 1996, $856 \mathrm{p}$.

UFV - Universidade Federal de Viçosa. Central de Processamento de dados (UFV/CPD). Manual de utilização do Programa SAEG (Sistema para Análises Estatísticas e Genéticas). Viçosa, MG: Universidade Federal de Viçosa, 2007, 59p.

Valadares, R.F.D.; Broderick, G.A.; Valadares Filho, S.C.; Clayton, M.K. Effect of replacing alfafa silage with high moisture corn on ruminal protein synthesis estimated from excretion of total purine derivatives. Journal of Dairy Science, 1999, 82, 12, 2686-2696.
Van Soest, P.J. Nutritional ecology of the ruminants. 2.ed., Ithaca: Cornell University. 1994, 476p.

Van Soest, P.J.; Robertson, J.B.; Lewis, B.A. Methods for extraction fiber, neutral detergent fiber and mostarch polysaccarydes in relation to animal nutrition cows. Journal Dairy Science, 1991, 83, 10, 3583-3597.

Visek, W.J. Ammonia metabolism, urea cycle capacity and their biochemical assessment. Nutrition Review, 1979 , 37, 9, 273-282,

Zeni, D. Nitrogênio Uréico no Leite de Vacas Mantidas em Pastagens de Aveia e Azevém. Universidade Federal de Santa Maria. Dissertação (Mestrado em Medicina Veterinária), 2010. 